\title{
MIXED REALITY BASED ENVIRONMENT FOR LEARNING SENSING TECHNOLOGY APPLICATIONS IN CONSTRUCTION
}

SUBMITTED: March 2021

REVISED: September 2021

PUBLISHED: November 2021

GUEST EDITORS: Nashwan Dawood, Farzad Pour Rahimian

DOI: $10.36680 /$ j.itcon.2021.046

Omobolanle O. Ogunseiju, Ph.D. candidate

Virginia Polytechnic Institute and State University, Virginia, United States

omobolanle@vt.edu

\author{
Abiola A. Akanmu, Ph.D \\ Virginia Polytechnic Institute and State University, Virginia, United States \\ abiola@vt.edu \\ Diana Bairaktarova, Ph.D \\ Virginia Polytechnic Institute and State University, Virginia, United States \\ dibairak@vt.edu
}

\begin{abstract}
SUMMARY: With the growing rate of adoption of sensing technologies in the construction industry, there is an increased need for technically skilled workforce to successfully deploy these technologies on construction projects. Inspired by opportunities offered by mixed reality, this paper presents the development and evaluation of a holographic learning environment that can afford learners an experiential opportunity to acquire competencies for implementing sensing systems on construction projects. To develop the content of the learning environment, construction industry practitioners and instructors were surveyed, and construction industry case studies on the applications of sensing technologies were explored. Findings of the surveys revealed sensing technologies domainspecific skill gap in the construction industry. Further, the findings informed the requirements of the learning environment. Based on these requirements, key characteristics of the learning environment are identified and employed in designing the environment. Still, a formative evaluation is important for developing an effective mixed reality learning environment for teaching domain-specific competencies. Thus, it is imperative to understand the quality, appropriateness, and representativeness of the content of the learning environment. This paper also presents a learnability assessment of the developed mixed reality learning environment. The assessment was conducted utilizing a focus group discussion with construction industry practitioners. Feedback was sought from the participants regarding the reflectiveness of the layout of the virtual environment of an actual construction site and the appropriateness of the represented construction applications. This study contributes to the definition of the type of domain-specific skills required of the future workforce for implementing sensing technologies in the construction industry and how such skills can be developed and enhanced within a mixed reality learning environment.
\end{abstract}

KEYWORDS: Mixed Reality; Sensing Technology; Education; Workforce; Holographic

REFERENCE: Omobolanle O. Ogunseiju, Abiola A. Akanmu, Diana Bairaktarova (2021). Mixed reality based environment for learning sensing technology applications in construction. Journal of Information Technology in Construction (ITcon), Special issue: 'Construction 4.0: Established and Emerging Digital Technologies within the Construction Industry (ConVR 2020)', Vol. 26, pg. 863-885, DOI: 10.36680/j.itcon.2021.046

COPYRIGHT: () 2021 The author(s). This is an open access article distributed under the terms of the Creative Commons Attribution 4.0 International (https://creativecommons.org/licenses/by/4.0/), which permits unrestricted use, distribution, and reproduction in any medium, provided the original work is properly cited. 


\section{INTRODUCTION}

Uncertainties arising from the complex nature of construction projects have necessitated the need for investing in sensing technologies to improve situation awareness of project teams. Some construction companies are currently utilizing vision-based sensing systems (e.g., laser scanners and cameras) and component-based sensing systems (e.g., Radio Frequency Identification (RFID), and Global Positioning System (GPS)) for resource tracking (Miller, 2008), safety (Beatty, 2016), productivity (Skanska, 2009) and quality management (Turner, 2016, Skanska, 2009). Miller (2008) reported using passive RFID tags to track precast concrete seats from fabrication to installation during a stadium construction project. Implementation of the RFID tags resulted in a reduction of the project schedule by 10 days and cost savings of one million dollars. Turner (2016) reported deploying GPS for locating existing utilities on an infrastructure project. This resulted in minimal retrofitting of the new utilities and consequently reduced labor and material costs.

Considerable efforts have also been made by researchers: Laser scanners and drones/Unmanned Aerial Vehicles (UAV) have been investigated for capturing as-built data to create 3D models of facilities (Huber et al., 2010, Turkan et al., 2012). RFID, GPS, and ultra-wideband technologies have been explored for material and equipment tracking on the jobsite (Song et al., 2006, Ko, 2010). According to Jang and Skibniewski (2009), tracking construction materials with RFID systems can yield up to $64 \%$ reduction in labor costs over two years. Similarly, the potentials of proximity sensing technologies for improving safety on the jobsite have been explored (Hallowell et al., 2010, Marks and Teizer, 2012, Teizer, 2008). For example, proximity sensors have been used for enhancing situation awareness by tracking workers' proximity to moving equipment (Oloufa et al., 2003, Choe et al., 2013), and automated construction vehicle navigation (Lu et al., 2007). Despite the efficacy and increasing deployment of these technologies, the construction industry is experiencing a shortfall of graduating construction engineering students and existing workforce equipped with the necessary skills to implement the technologies on construction projects (Hannon, 2007, Kapliński, 2018). This opinion was also shared by Zhang and Lu (2008) who posited that students are unaware of the potentials of sensing technologies in the construction industry.

For construction engineering students to acquire technical skills for implementing sensing technologies, it is pertinent to engage them in hands-on learning with the technologies. However, inaccessibility to construction sites for experiential learning and in some cases, high upfront costs of acquiring sensing technologies are encumbrances to equipping construction engineering students with the required technical skills. One way to reduce these barriers is by augmenting digital 3D representations of construction sites and sensing technologies in the form of an interactive holographic scene (HS), a concept of mixed reality, into the physical classroom so that students can explore the technicalities involved in deploying sensing technologies on construction projects. With an interactive holographic learning environment, students can access different difficult situations that are too dangerous to access on real construction sites. The use of the term 'holographic' is meant to refer to augmented reality that appears to users as 3D objects existing in the physical world as popularized by Microsoft.

This study employed Mixed Reality (MR) for equipping construction engineering students with hands-on learning experience. The following section presents a review of the literature on the application of MR as a learning environment in Construction Engineering and Management (CEM) Education.

\section{LITERATURE REVIEW}

\subsection{Mixed Reality Learning Environment}

The emergence of digital learning environments such as virtual reality (VR) and MR has spurred a prolific interest amongst researchers and educationists owing to its ability to experientially engage students in a social learning environment. The application of VR environments to enhance education has been embraced in medicine (Liu, 2014), construction (Messner et al., 2003), and industrial (Maffei and Onori, 2019) engineering programs. According to (Pantelidis, 2010), VR leverages visualization techniques for enhancing the comprehension of abstract classroom concepts. However, the immersive feature of VR environments restricts self-localization of participants in the virtual and real-world (Psotka, 1995). All senses of participants are actively engaged in the virtual environment. Hence, participants may struggle to simultaneously maintain their position in the virtual and real world. Azhar et al. (2018) who introduced VR for teaching design communication reported that students immersed in a VR learning environment can become motion sick and unstable and often require more supervision from instructors. Contrary to VR, AR involves superimposing or overlaying virtual objects on the real world- 
environment (Lu Lu, 2019), while MR merges the real and virtual environment (Fig. 1), or integrates real-world objects into a virtual environment (Pan et al., 2006). The difference between AR and MR is described by Lehman and Tan (2021) as 'a sliding scale'. According to the authors, AR can be described as a simple integration of a virtual object in the real world, while MR can be considered as imposing multiple scripted virtual objects in the real world. In this way, students are consciously aware of the real world while engaged in the virtual learning environment. Through active engagement in the learning process, MR has been proven to improve students' learning of spatial structure, and long-term retention of what is taught in the environment (Radu, 2014). MR learning environment affords students a hazard-free sharable virtual learning environment that can accommodate multiple learners (Pan et al., 2006). Furthermore, Azhar et al. (2018) who reported the efficacy of MR in improving design communication skills in construction education, concluded that MR was more effective for educating construction students about design plans when compared to traditional design reading processes. The study further revealed the potentials of MR for supporting hands-on learning in the classrooms.

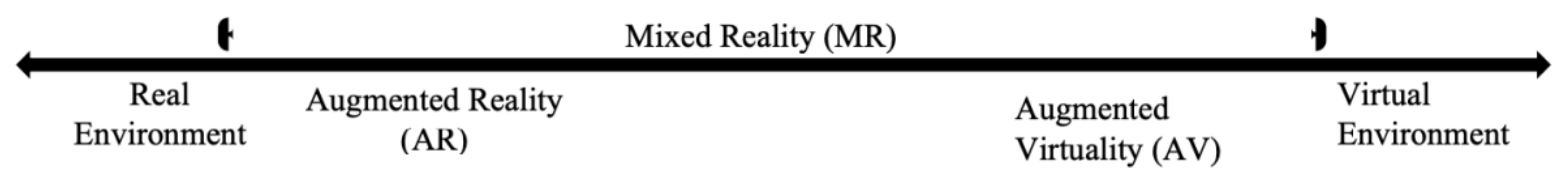

FIG. 1: Reality-Virtuality Continuum (Milgram and Kishino, 1994).

\subsection{Mixed Reality in Construction Engineering and Management Education}

The effectiveness of MR and other immersive technologies as a hazard free learning environment has been explored for construction workforce training and education. Getuli et al. (2020b) adopted an immersive VR environment based on Building Information models (BIM) to simulate a construction activity for enhancing workspace planning. Similarly, several studies have explored the efficacy of immersive technologies for workforce health and safety training (Getuli et al., 2020a, Getuli et al., 2018, V. Getuli et al., 2020, Bosché et al., 2016, Getuli et al., 2019). In construction education, studies have explored the effectiveness of MR as a pedagogical intervention. Azhar et al. (2018) investigated the potentials of MR and VR to enhance building construction students' for developing competencies for design review and assessments. By comparing learning in VR and MR environments, the authors asserted improved active learning amongst the students. Wu et al. (2020) explored the potential of an MR environment for training students on construction wood framing in a laboratory. The authors reported comparable construction productivity for students learning with and without the MR environment. Shanbari et al. (2016) incorporated jobsite experience in construction management classes by augmenting complex construction processes like masonry and roof work into the classroom. Students who were exposed to the augmented site remembered and identified the processes more effectively than those who were not. Kim and Irizarry (2020) evaluated the use of AR for improving spatial skills of construction management students. Shirazi and Behzadan (2015) designed and assessed an AR information delivery tool for improving traditional based learning in construction and civil engineering curriculum. The authors reported that the AR tool enhanced cognitive process, and motivated learning amongst the students. Concerning safety education, Tixier et al. (2013) developed and assessed an augmented reality tool for teaching construction hazard recognition to construction engineering and management students. As regards MR environment for learning construction technologies, Vasilevski and Birt (2020) reported students' experiences like simulated learning, and improved engagement, while learning BIM in a mixed reality environment.

Sensing technologies is an emerging area in the construction industry, and there is a need to prepare the future workforce to meet the industry's demands. However, scarce studies have reported the impacts of MR for teaching sensing technologies and providing hands-on learning in construction education. In this research, empirical data is collected on the required competencies for deploying sensing technologies and further implemented to design and develop a MR environment for teaching sensing technologies. A formative evaluation by construction experts was conducted to improve the learnability of the environment. 


\section{THEORETICAL UNDERPINNING}

The development and evaluation of the holographic learning environment is grounded in competence-based theory and can be viewed from the lens of learning for use (LfU) design framework. Competence-based theory involves connecting classroom learning with activities in the workplace for an accurate representation of the workplace and an easier transition of students into the workforce (Gonczi, 1999). This study supports this theory by identifying and incorporating the required competencies for deploying sensing technologies in the construction industry, in the holographic learning environment.

LfU framework is based on the following four tenets: “(1) knowledge construction is incremental; (2) learning is goal-directed; (3) knowledge is situated; and (4) procedural knowledge needs to support knowledge construction" (Edelson, 2001). Tenets 1 and 4 asserts that there is incremental development of new knowledge and procedures when students' prior knowledge is tied to new knowledge. For example, students use foundational knowledge of construction operations to recognize resources, activities, and project risks. By employing the structured process in Fig. 3, the holographic learning environment enhances students' engagement in an incremental process. Students incrementally build knowledge by adding new concepts to memory, while making new connections between concepts. This new knowledge equips students to become proactive in their learning and to construct solutions to construction problems requiring sensing systems. This also supports the notion of the constructivist learning theory which posits that students develop knowledge of a particular topic by being actively engaged in a social learning environment (Bada and Olusegun, 2015).

Tenets 2 and 3 asserts that knowledge acquisition is goal-directed and situated. Theorists Greeno (1998) and Lave and Wenger (1991) argue that knowledge should not be delivered in the abstract but in the context. The situative perspective views knowledge "as distributed among people, their environments and the communities of which they are a part" (Greeno and Engeström, 2006), and learning is conceptualized as meaningful participation in a community of practice. The realization of gaps in one's knowledge as a result of specific competency demands in the workplace or self-curiosity can serve as a motivational goal for acquiring new knowledge. For example, the learning activities within the holographic learning environment are developed based on formal skills and knowledge established in collaboration with industry practitioners. These real-life activities will enable students to engage in goal-directed tasks and situated learning by beginning with an overarching goal or problem and then implementing suitable sensing systems.

\section{RESEARCH OBJECTIVES AND CONTRIBUTION}

This study introduced the development and formative evaluation of a MR learning environment in the form of HS for bridging the technical skill gap of construction engineering students in deploying sensing technologies on construction projects. To develop the learning environment, the required competencies for implementing sensing technologies on construction projects were identified through a survey of industry practitioners and online case studies of industry applications. The study also explored the extent to which the sensing technologies are taught in construction engineering programs by surveying faculties across the United States (US). The results from the surveys and case studies provided the required competencies for deploying sensing technologies on construction projects. Based on these competencies, the learning contents of the HS were identified. This paper elucidates preliminary findings from the surveys and case studies, and evaluation of the learning environment. Implications of the findings and the interactive learning environment for bridging the technical skill gap in the construction industry are also discussed.

\section{METHODOLOGY}

The development and evaluation of the learning environment were guided by the methodology detailed in Fig. 2. The contents of the learning environment were procured through (1) surveys of industry practitioners and faculty members, and (2) collection of industry case studies on the sensing technologies deployed on construction projects. To provide evidence to support the need for the study, construction engineering instructors in institutions in the US were surveyed to capture the extent to which sensing technology-related contents are being taught.

The required competencies and learning content for the HS environment were identified via an online survey of industry practitioners across the US. The survey data were analyzed using cluster analysis and descriptive tools such as averages and percentages. The study further performed content analysis of the industry case studies on the 
applications of sensing technologies. To extract the required competencies from the survey results and case studies, a mind mapping of identified applications of sensing technologies was conducted using a readily available mind mapping application. The sensing technologies and applications were modeled in the HS environment using Unity game engine. Specific learning contents were guided by a general set of characteristics identified from the surveys and case studies, and taxonomic models of the operational characteristics of sensing technologies. Learnability assessment was conducted with a focus group of industry practitioners to assess the developed learning environment. Participants were industry practitioners identified from the survey as adopting sensing technologies on their projects. Data from the learnability assessment were transcribed and thematically coded to illustrate the key feedback on the learning contents of the environment. All data collection was conducted under the approval of the Institutional Review Board (IRB) at Virginal Tech.

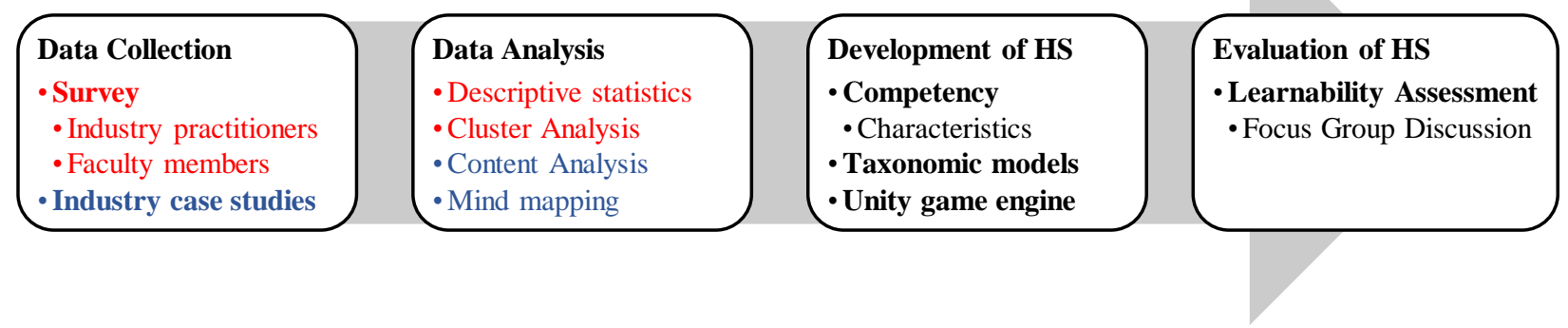

FIG. 2: Research methodology (The color in the figure indicates the data collection method and the corresponding analysis method).

\subsection{Data Collection}

\subsubsection{Survey}

A total of 73 industry practitioners from 46 construction companies in the US were surveyed to obtain their perceptions on sensing technologies in the industry. The online survey included closed-ended questions regarding the types of sensing technologies currently deployed by construction companies, the current level of adoption of the sensing technologies, future sensing needs of construction companies, and skills required of the future construction engineering workforce to implement the sensing technologies on projects. The survey also included open-ended questions on the specific current and future construction applications of sensing technologies. Responses from the survey provided detailed information on the competencies and learning objectives for the HS. Further details on the characteristics of the respondent's companies are provided in Table 1.

Table 1: Company size of industry participants.

\begin{tabular}{lc}
\hline Company size based on number of employees & Number \\
\hline $10-50$ employees & 9 \\
\hline 50 - 100 employees & 4 \\
\hline $100-500$ employees & 14 \\
\hline More than 500 employees & 15 \\
\hline
\end{tabular}

The study also surveyed a total of 37 faculty members across the US to understand the state of sensing technologies in construction engineering education. Generally, the faculty members were surveyed to obtain data on the percentage of institutions currently teaching sensing technologies curriculum. Close-ended questions were asked to obtain data on the extent to which sensing technologies are being taught in these institutions.

\subsubsection{Industry case studies}

To acquire a rich set of applications of sensing technologies in the construction industry, online construction industry case studies were reviewed. This involved surveying and documenting cases where different sensing technologies have been implemented on construction projects. A general survey of case studies on construction companies' websites was first conducted. This yielded a total of 17 case studies of laser scanners, drones, RFIDs, and ground-penetrating radars, and GPS from different companies. Thereafter, a thorough web search using "Laser 
scanner case studies in construction companies" search string was used. "Laser scanner" was then replaced in the search string with each sensing technology. The search was further filtered by omitting search results without the exact words "Sensing technologies", and "construction". Search results from marketers and developers of sensing technologies providers were excluded from this study. The web search produced 14 case studies for only laser scanners. Consequently, a total of 31 industry case studies were considered in this study. Construction applications from these case studies were analyzed for identifying the characteristics of the HS learning environment.

\subsubsection{Learnability assessment}

To assess the developed learning environment for teaching sensing technologies, a learnability assessment was conducted as a formative evaluation of the learning environment with construction industry practitioners deploying sensing technology. As explained by Weston (2004) and Deutsch et al. (2005), formative evaluation is a domain expert review that focuses on design improvement, curricular contents, and usability of a learning environment. The objectives of the learnability assessment were to assess the extent to which the layout of the virtual construction site was reflective of a real job site, and to understand the extent to which each represented activity for each virtual sensor are reflective of their applications on the jobsite. Participants were industry practitioners proficient in the use of the represented sensing technologies. Owing to the constraints and restrictions posed by the COVID-19 pandemic, such as social and physical distancing, in-person research involving groups in close proximity has been limited greatly (Clay, 2020). This informed different approaches to remotely conducting human-computer interaction research using effective video conferencing tools. Remote user evaluation has long been explored, and studies such as Tullis et al. (2002), Andreasen et al. (2007) have reported its effectiveness. Therefore, the learnability assessment was conducted online as a synchronous focus group discussion with construction experts via Zoom. Zoom was selected as the platform for the focus group discussion because of the screen sharing feature which is an important tool for remote virtual environment evaluation (Thomsett-Scott, 2006). To better improve the virtual navigation and familiarity with the environment, participants were provided a guided video of the environment prior to the focus group discussion, which according to Chrastil and Warren (2013) is effective for evaluating virtual environments.

Guided by the focus group questions, the researcher moderator mirrored the HS environment via screen-sharing, and guided the participants through the learning contents to simulate a virtual cognitive walkthrough of the learning environment. Comments were provided similar to a think-aloud protocol and the focus group discussion session was video recorded. After the focus group discussion, participants were mailed a short questionnaire on demographics. The questionnaire entailed questions on age, sensing technologies used, years of experience in the construction industry and with the use of sensing technologies, and experience with MR or VR environments.

\subsection{Data Analysis}

\subsubsection{Survey}

Survey data on the types of sensing technologies currently deployed by construction industries, the current level of adoption of the sensing technologies, future sensing needs of construction companies, and skills required of the future construction engineering workforce to implement the sensing technologies on projects were analyzed using descriptive tools. Open-ended questions on different construction applications of sensing technologies were analyzed to categorize similar construction applications/activities for each sensing technology using cluster analysis.

\subsubsection{Industry case studies}

Content analysis of identified industry case studies of construction applications of sensing technologies was conducted. The contents of each case study were classified based on the case study title, sensing technology adopted, specific construction activities, meta-description of the activity, identified benefits of the sensing technology, and appropriate website links to the case study. Similar construction applications from the survey and industry case studies of each sensing were grouped and presented in Table 1 and 2. As seen in Table 2, imagebased sensing technologies are widely used and have more applications than component-based sensing technologies (see Table 3). 
Table 2: Image-based sensing technologies construction applications

\begin{tabular}{|c|c|c|}
\hline Sensors & Survey & Case studies \\
\hline \multirow{8}{*}{$\begin{array}{l}\text { Laser } \\
\text { scanner }\end{array}$} & $\begin{array}{l}\text { Existing conditions for site } \\
\text { coordination }\end{array}$ & Existing conditions for hall renovation. \\
\hline & Procuring as built drawings & Capturing scans for complete 3D or 4D modeling. \\
\hline & $\begin{array}{l}\text { Layout of underground MEP before } \\
\text { slab pour }\end{array}$ & As-built information for a medical building project. \\
\hline & Floor flatness and level testing & $\begin{array}{l}\text { Concrete floor flatness for a medical project that required } \\
\text { installation of sensitive equipment. }\end{array}$ \\
\hline & Setting grades & Stockpile quantification for auditing purposes. \\
\hline & Site layout & \\
\hline & Detecting security fence & \\
\hline & In-wall rough scans & \\
\hline \multirow[t]{6}{*}{ Drone } & $\begin{array}{l}\text { Inspection and observation of } \\
\text { construction processes }\end{array}$ & Site progress monitoring using drone images and videos. \\
\hline & Quantify stockpiles & Inspect difficult-to-reach areas on the jobsite. \\
\hline & Site documentation & $\begin{array}{l}\text { Tracking structural changes of an abandoned tunnel for renovation } \\
\text { work. }\end{array}$ \\
\hline & Locating embeds in decks & Procurement of images for advanced digital modeling. \\
\hline & Locating post-tensioned cables & Documentation of structural fills for a health care project. \\
\hline & Marketing & \\
\hline GPR & $\begin{array}{l}\text { Locating reinforcement bars, and } \\
\text { underground utilities }\end{array}$ & $\begin{array}{l}\text { Wall deviation and issues hidden behind wall surfaces for } \\
\text { renovation purposes. }\end{array}$ \\
\hline
\end{tabular}

Table 3: Component-based sensing technologies

\begin{tabular}{|c|c|c|}
\hline Sensors & Survey & Case studies \\
\hline \multirow[t]{6}{*}{ RFID } & Monitoring workers on site & Attached to workers' hardhats to track safety. \\
\hline & Tracking materials installation progress & $\begin{array}{l}\text { Track precast concrete from design, detailing, } \\
\text { fabrication, production, up till the installation phase. }\end{array}$ \\
\hline & Operation and maintenance information & \\
\hline & Locating workers on the jobsite & \\
\hline & Tracking equipment and materials inventory & \\
\hline & Tracking delivery of materials to site & \\
\hline \multirow[t]{8}{*}{ GPS } & Site grading & Locate electrical components in precast concrete. \\
\hline & Automated machine guidance & Earthwork equipment navigation. \\
\hline & Tracking rented equipment productivity & $\begin{array}{l}\text { Location of storm water, sewer and telephone lines for } \\
\text { HVAC systems renovation. }\end{array}$ \\
\hline & Tower crane setup & \\
\hline & Location of utilities and embeds & \\
\hline & Digital layout & \\
\hline & Laser scanner localization & \\
\hline & Detection of security fence & \\
\hline \multirow[t]{2}{*}{ IMU } & Detection of falls and injuries & \\
\hline & Excavation support & \\
\hline
\end{tabular}




\subsubsection{Learnability assessment}

After approval from the IRB, participants who indicated that they are deploying sensing technologies were invited for the learnability assessment in the form of focus group discussion. Five interested participants were scheduled for the learnability assessment which was conducted via Zoom and video recorded. Comments from the virtual walkthrough of the environment were first transcribed using Otter.ai application. The transcripts were evaluated and updated by a thorough analysis of the recorded video. The transcripts were then sent to participants for member checking. The corrected transcripts were de-identified and coded using NVIVO (release 1.3 (535)). The codes were broadly classified into two: layout of the environment and representativeness of construction activities for each sensor. These codes were further delineated into child codes based on the appropriate comments from the participants. For each focus group question, similar themes were searched out within codes to further categorize the data, and identical themes were summarized and represented in a table. To ensure accuracy, identified themes were compared with the transcript.

\subsection{Development of Holographic Scene Learning Environment}

\subsubsection{Overview of Developmental Process}

Guided by the tenets of LfU, the overall design of the environment was based on hierarchical task analysis, to structurally organize tasks sequence and scaffold student's learning in the environment. The HS learning environment was divided into three hierarchies: (1) Explore jobsite scene; (2) Sensor tutorial scene; and (3) Sensor implementation scene (see Fig. 3). The first hierarchy (i.e., Explore the jobsite scene) aims to situate students in their domain. Students are presented with a series of construction activities, and they can selectively explore resources, task operations, and workspaces of each activity. To aid this, each activity workspace was annotated, and resources were listed using Mixed Reality ToolKit (MRTK) tooltip. Thereafter, dynamically spawning tooltips were attached to annotate each resource using the 'show on focus' feature. This feature was harnessed to reduce cognitive overload of the students while exploring each activity on the jobsite. After situating students in their domain, students can proceed to 'Sensor tutorial scene' where concise information and procedural knowledge of each sensor are presented to them. This scene features only one activity per sensor, and students are guided to implement selected sensor to address risks or track productivity of resources in the activity. To further guide students in this scene, air tapping was simulated to demonstrate how resources can be manually tagged using component-based sensors. This scene encourages students to construct their own technical skills of the represented sensing technologies. After learning how each sensor works, students can proceed to the 'Sensor implementation scene', where they perform selective implementation of sensing technologies on construction activities. To enhance easy navigation of the environment, the 'Chevron' button was employed to direct students to the location of selected activity. Each activity also had the show/Hide button that conceals other irrelevant resources in the environment, reduces cognitive workload of students, and improves attention to the required tasks.

\subsubsection{Developmental Framework of the HS learning environment}

The survey and case studies results guided the characteristics of the learning environment. These characteristics were categorized into two: (1) the jobsite characteristics, which are the identified construction applications of each sensing technology, and (2) the operational characteristics of each sensing technology. The applications of the sensing technologies were extracted from Tables 2 and 3 to establish the jobsite characteristics. For each sensor application, the suitable construction resources (i.e., equipment, personnel, and materials) were determined (see Table 4).

Furthermore, to represent the operational characteristics of each sensing technology, the features and functionalities of sensors were explored. Taxonomic models entailing the hierarchal development of image-based sensing technologies were used to guide the developmental process. While image-based sensors were represented as game objects, component-based sensors were scripted to the appropriate construction activities. This is because image-based sensors require substantial operational skills before data collection. For example, laser scanning skills include placement options, tripod stand leveling, and interaction with the scanner interface. On the other hand, represented component-based sensors require more decision-making skills such as exploring the activities and identifying the context for the use of the sensors. To develop the taxonomic model for the laser scanner (Fig. 4), operational characteristics of commercially available scanners (e.g., Trimble X8 and FARO Focus M70) were reviewed to determine the steps for operating the virtual laser scanner. Similarly, the taxonomy for drones (Fig. 5) 
was developed by exploring the functionalities of Da-Jiang Innovations (DJI) drone. The controller was modeled to include features for controlling the movement of a typical drone.

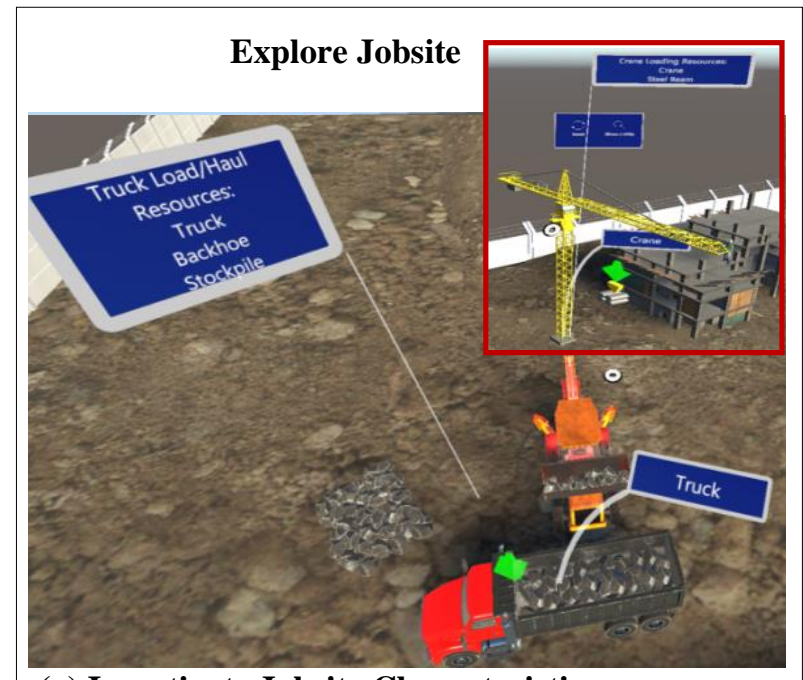

(a) Investigate Jobsite Characteristics

Explore tasks, operations, dependencies, workspaces; Identify resources and risks.

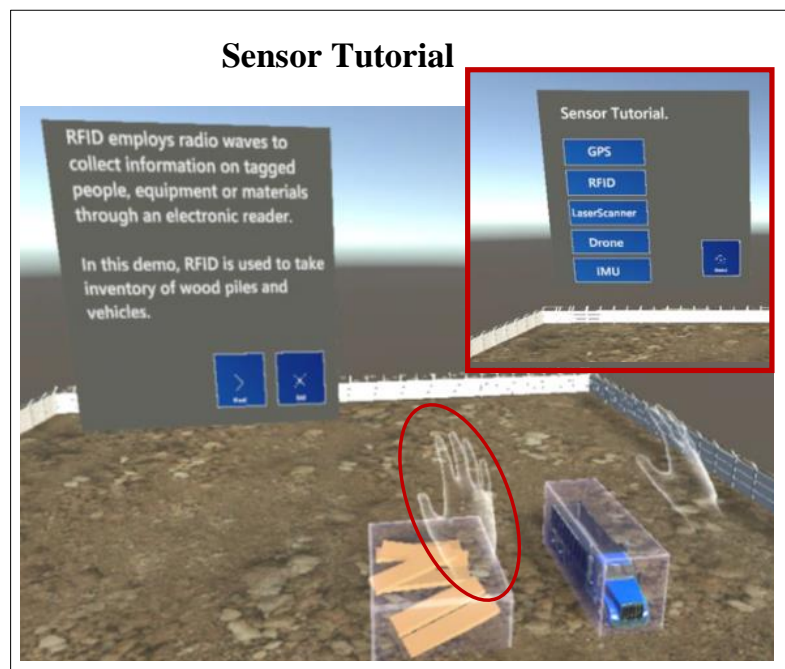

(b) Explore Sensing Technologies

Select sensor; Explore sensors' functionalities and applications.

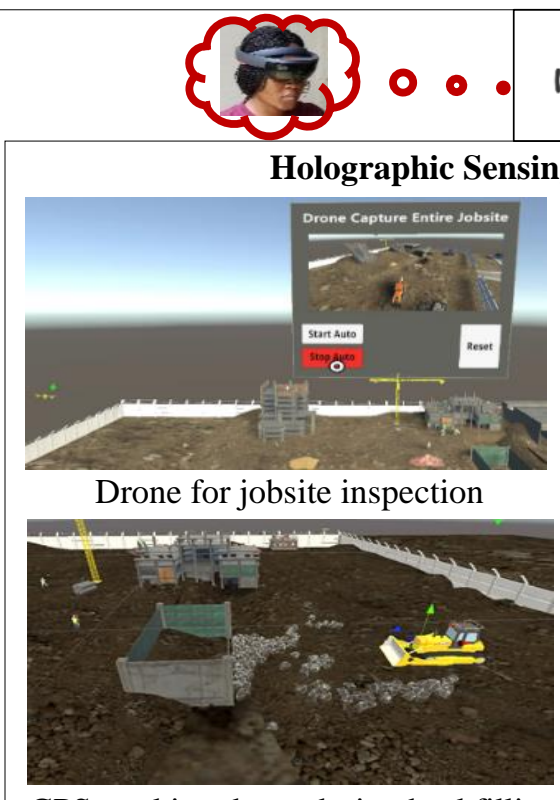

GPS tracking dozer during backfilling

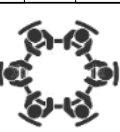

(c) Perform selective implementation

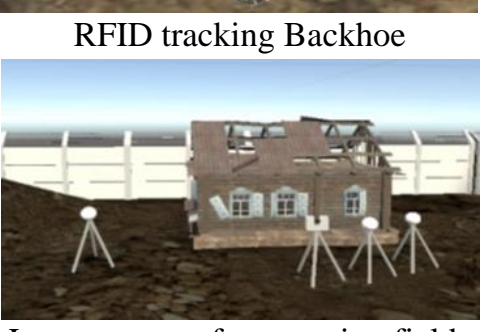

Laser scanner for scanning field conditions

FIG. 3: Holographic Environment for Learning Sensing Systems. 


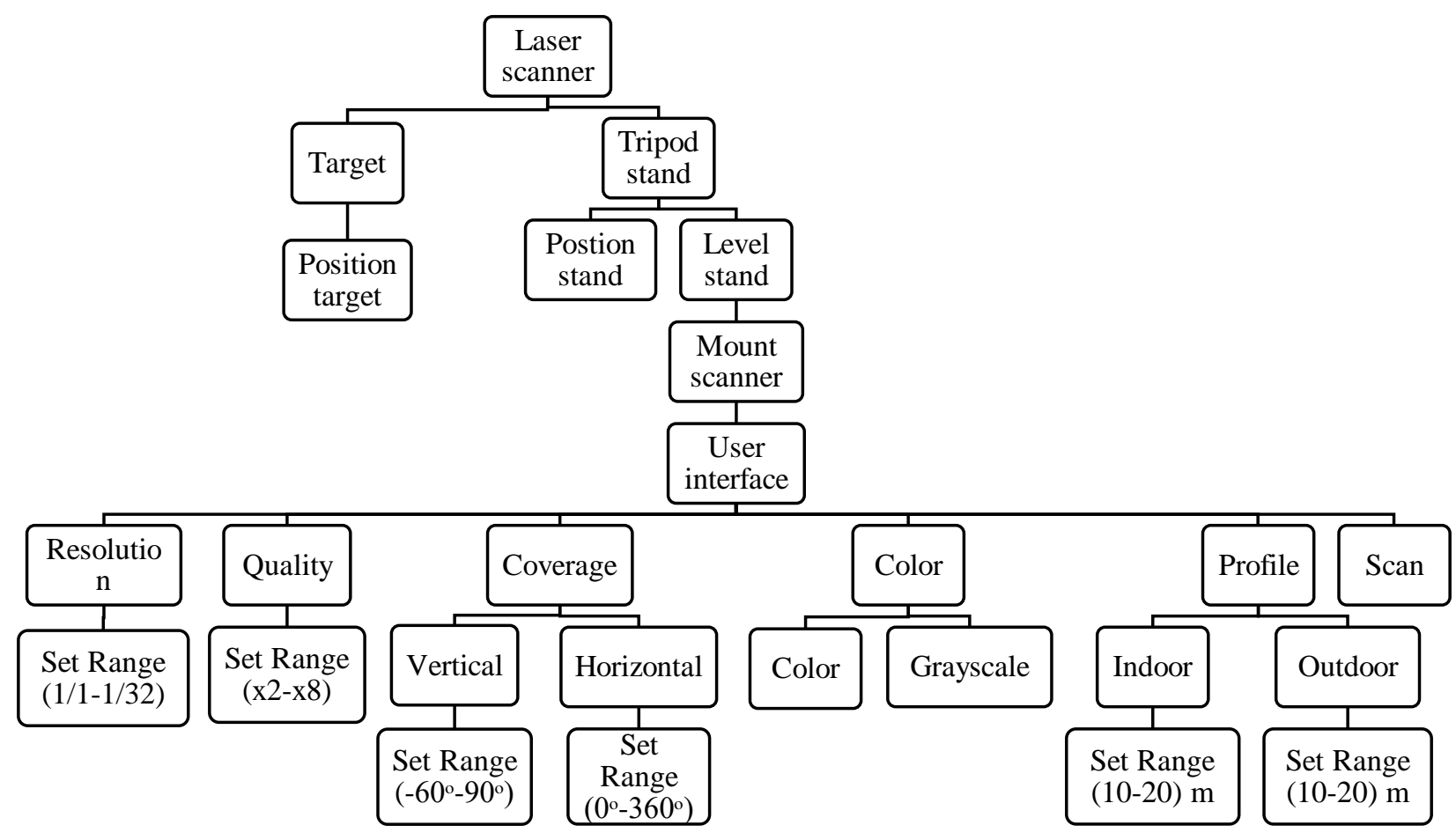

FIG. 4: Taxonomy of operation of virtual laser scanners in the HS.

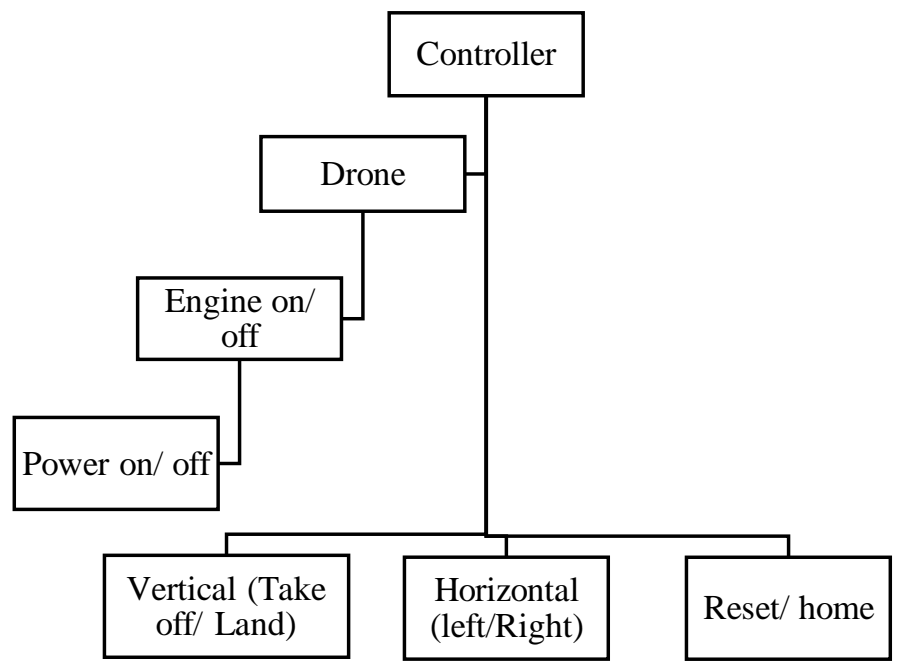

FIG. 5: Taxonomy of operation of virtual drone in the $H S$.

\subsubsection{System Architecture of HS Learning Environment}

The system architecture of the HS learning environment consists of the holograms developed using Unity game engine, viewed and interacted-with using a HoloLens. The Unity game engine comprises of GameObjects, MRTK toolkit, and services (Fig. 6).

\section{GameObjects}

The GameObjects in the learning environment entail the digital representations of the jobsite characteristics and the virtual sensing technologies. Each GameObject consists of components that provide the required functionalities and essence of the learning environment. The GameObjects are the construction site, equipment, personnel, materials, sensors, holographic buttons, chevron and reports. The construction site includes basic GameObjects that define the structure of the learning environment such as activities, terrain, fence, and road. As depicted in 
Table 4, a total of 15 construction activities (and the associated resources) were represented in the learning environment.

\section{Equipment, materials, and personnel}

As shown in Table 4, the equipment are construction vehicles such as dozer, truck, and crane. The equipment were animated based on the required functionalities, for example, the backhoe was animated to pick up stones and fill the truck. Each equipment had collider and Rigidbody component that allowed the vehicles to act like real objects under gravity. Similar to the equipment, personnel/workers were animated based on the work tasks performed by construction trades. For example, a carpenter was animated to interact with wooden materials, while a painter was animated to perform painting task using a paint roller. Materials were not animated but had Rigidbody component to balance forces and collisions from other GameObjects. For example, it was important to increase the mass of the stockpile in backfilling activity to enhance the required physics with the dozer. Based on the objective of the activity, the resources in each activity were sequenced with scripts. The scripts were written in C\# programming language in Visual Studio to allow responses to inputs from students, and enable control and coordination of the learning environment.

\section{Sensors}

Represented sensing technologies were developed as GameObjects based on their functionalities. For example, the laser scanner which comprised of tripod stands, scanner, and targets had a box collider and Rigidbody. This was important owing to the expected interactivity of the laser scanner components, as it is expected that students would move the tripod stand around and position them at choice locations. On the other hand, the drone was animated to fly around the jobsite based on inputs from the controller. Component-based sensors such as RFID, GPS, and IMU only comprised of scripts that guided the decision-making process of the students. For example, on tagging a truck with GPS, during 'truck load/haul' activity, the GPS report is triggered and displays coordinates of the truck as it moves to unload the stockpile.

\section{Holographic button and Reports}

The holographic buttons are menu interface that allow inputs into the environment and controls the required scripts which in turn manipulates the GameObjects. The learning environment also includes important GameObjects like the chevron button that provides easy navigation in the environment. The chevron consists of mesh collider, mesh renderer and scripts and provides directional information in the environment. To convey more information about the GameObjects such as activities names, resource lists, and resources names, MRTK tooltips were leveraged. The reports are additional GameObjects that display data outputs for each sensing technology. The reports are usually scripted with the respective sensor and show up as a canvas on the interface of the learning environment.

\section{Services}

The services enhance the user experience when using HoloLens (Akanmu and Olayiwola, 2019). As the students interact with the learning environment, their interactions are related to a first-person avatar.

\section{Mixed reality toolkit (MRTK)}

The MRTK in the HS creates interactivity when students are immersed in the holographic environment using the HoloLens. The MRTK consists of camera, gaze, hand, and cursor that enables the usability of the learning environment in an MR environment using the HoloLens. For example, the camera system allows the MRTK to optimize HoloLens' camera to capture and display the MR environment. The input system profile includes gaze, cursor, and hand tracking which enables the students to focus on any game object by placing it in the center holographic scene.

\section{Hologram}

The Microsoft HoloLens only allows for the selection of objects through hand gestures such as air-tapping. To access the learning environment as hologram, the HoloRemote is activated on HoloLens HMD and connects to the learning environment through internet. 
Table 4: Represented activities, resources and sensors.

\begin{tabular}{|c|c|c|c|c|}
\hline \multirow[b]{2}{*}{ Activities } & & \multirow[b]{2}{*}{ Sensors } \\
\hline & Equipment & Material & Personnel & \\
\hline Dozer backfilling & Dozer & Stockpile & & GPS \\
\hline Crane loading & Crane & Steel Beam & Supervisor & GPS \\
\hline Materials delivery & Truck & Rebar in truck & & GPS \& RFID \\
\hline Material Handling (1) & & & Worker 1 & GPS \& RFID \\
\hline Truck Load/Haul & Loader \& Truck & stockpile & & GPS \& RFID \\
\hline Material Inventory & & Log, steel, wood & & RFID \\
\hline Material Handling (2) & & & Worker $1,2, \& 3$ & RFID \& GPS \\
\hline Cladding & & Building 1 & & Laser scanner \\
\hline Flooring & & Matte slab & & Laser scanner \\
\hline Stockpile unloading & & Stockpile $1 \& 2$ & & Laser scanner \\
\hline Renovation & & Old building & & Laser scanner \& Drone \\
\hline Site inspection & & Overall jobsite & & Drone \\
\hline Painting & & Building 2 & Painter & IMU, GPS \& RFID \\
\hline Labor work & & & Labor & IMU, GPS \& RFID \\
\hline Carpentry & & & Carpenter & IMU, GPS \& RFID \\
\hline
\end{tabular}

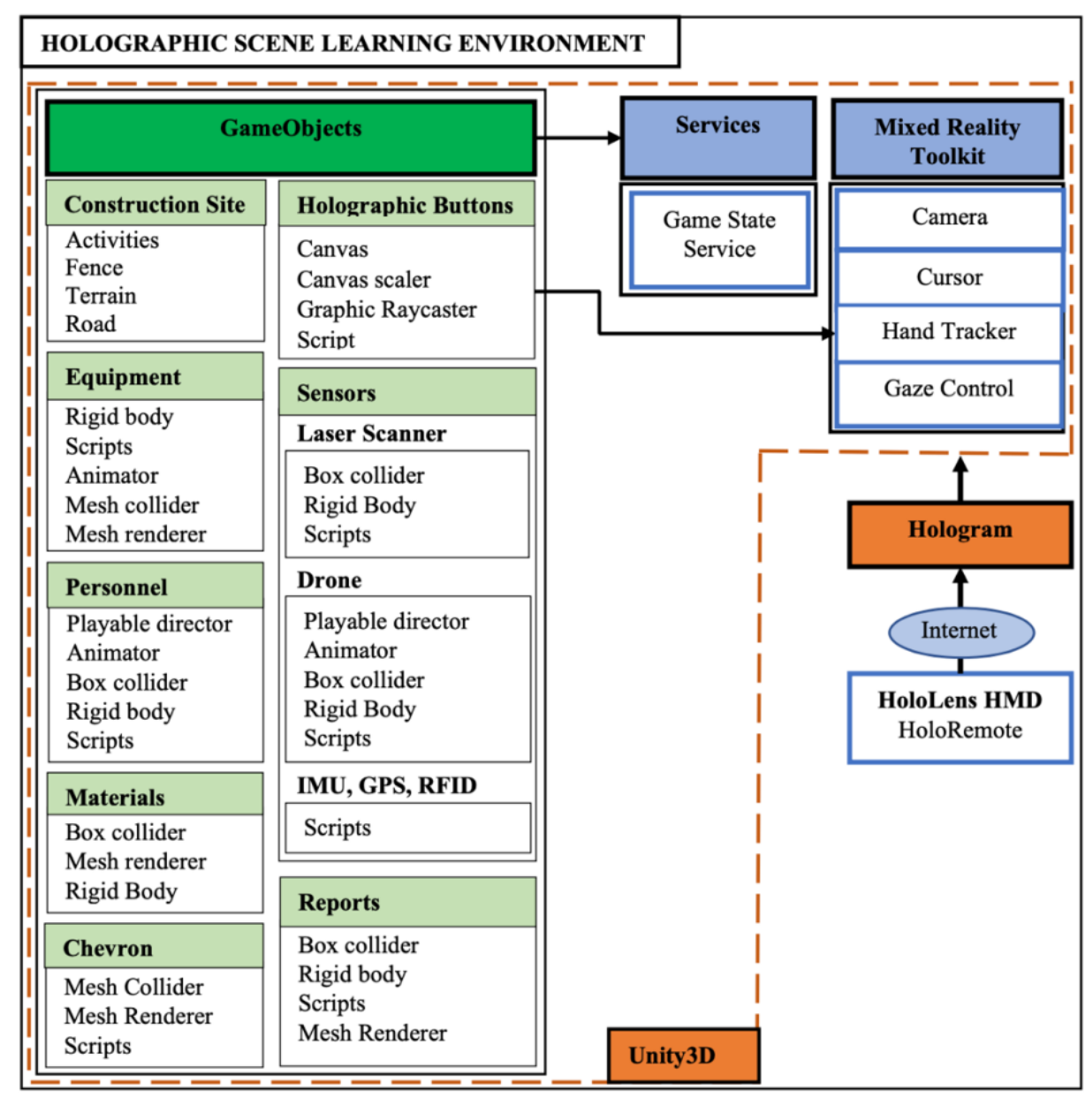

FIG. 6: System architecture of the holographic learning environment adapted from (Akanmu and Olayiwola, 2019). 


\section{RESULTS}

This section presents the results of the online survey and industry case studies of construction applications of each sensing technology. The developed HS with an example of stockpile measurement using a laser scanner was further elucidated, and results from professional evaluation of the learning environment is presented.

\subsection{Survey Results}

\subsubsection{Industry Practitioners Survey}

Preliminary results from the construction industry survey indicated a high rate of adoption of sensing technologies. $80 \%$ of the surveyed construction companies have started adopting sensing technologies while $20 \%$ are yet to adopt sensing technologies on their projects (Fig. 7). Fig. 8 revealed the rate of adoption of each sensing technology in the industry, with cameras and laser scanners, GPS, RFID, and drones being the most frequently deployed on construction projects. Respondents from the construction industry were asked to suggest sensing technologies to be included in construction engineering education. Fig. 9 shows the sensing technologies suggested by industry practitioners for inclusion in construction engineering education. Over $90 \%$ of the respondents suggested that laser scanner should be included in construction engineering education. The top 5 suggested and frequently adopted sensing technologies were represented in the HS.

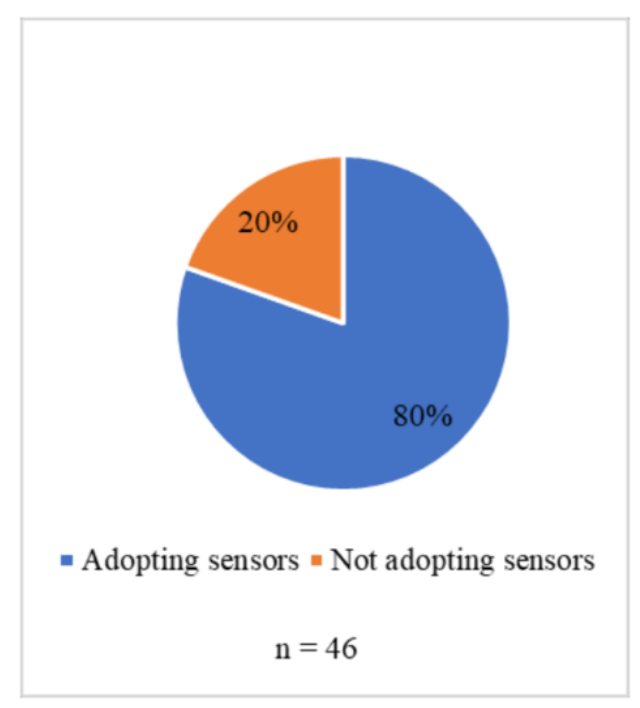

FIG. 7: Level of adoption of sensing technologies.

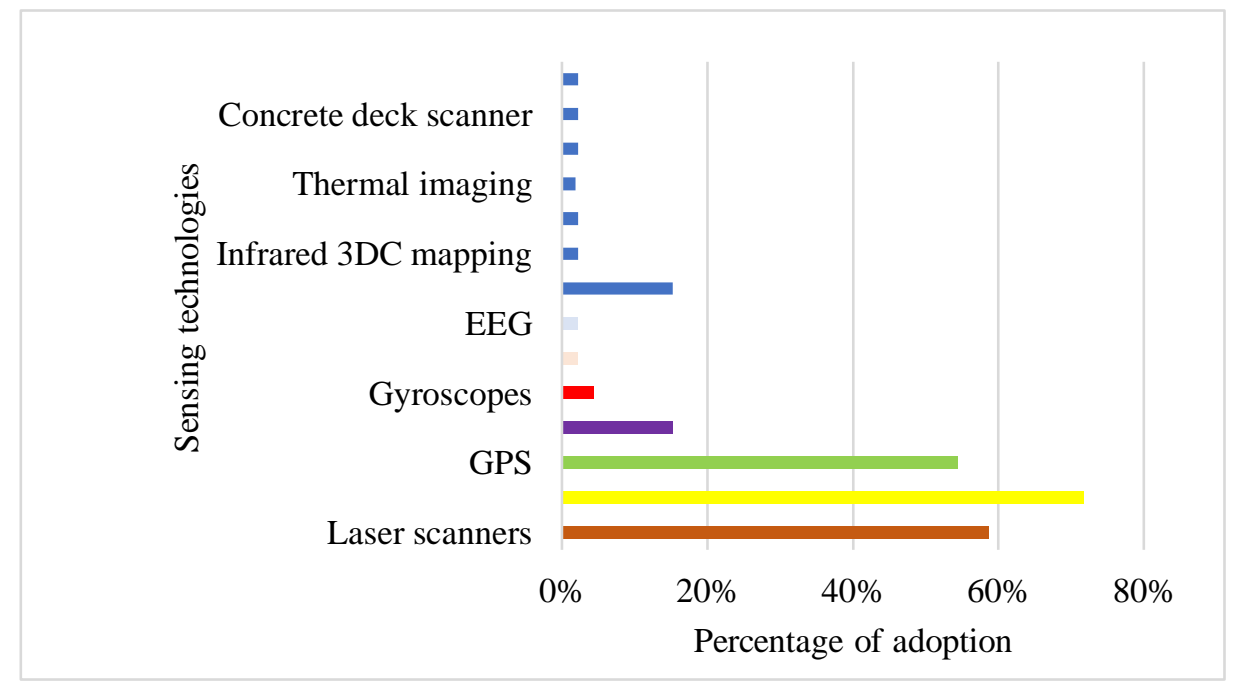

FIG. 8: Adoption rate of each sensing technologies. 


\subsubsection{Faculty survey}

Instructors from different institutions across the US were surveyed to explore the extent to which sensing technologies are currently taught in construction engineering education. Fig. 10(a) shows that $54 \%$ of the respondents have started teaching sensing technologies while $46 \%$ are yet to include sensing technologies in their curriculum. Fig. 10(b) reveals the percentages of institutions already teaching each sensing technologies in construction education. Similar to the high adoption rate of laser scanner in the industry (Fig. 8), most faculty members have started including laser scanners in their curriculum. Results also revealed that as proposed by the industry (Fig. 9), laser scanners, cameras, GPS, RFID, and accelerometer are the top 5 sensing technologies taught to students. However, the surveyed universities have not started incorporating drones in their curriculum.

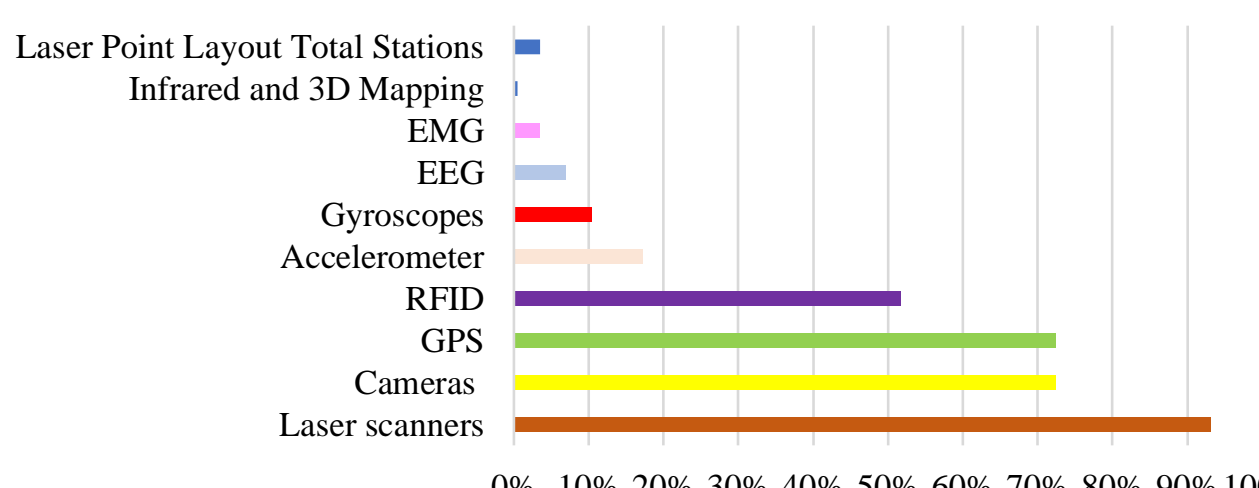

$0 \% \quad 10 \% \quad 20 \% \quad 30 \% \quad 40 \% 50 \% \quad 60 \% \quad 70 \% \quad 80 \% 90 \% 100 \%$

FIG. 9: Suggestions for the inclusion of sensing technologies in construction education.

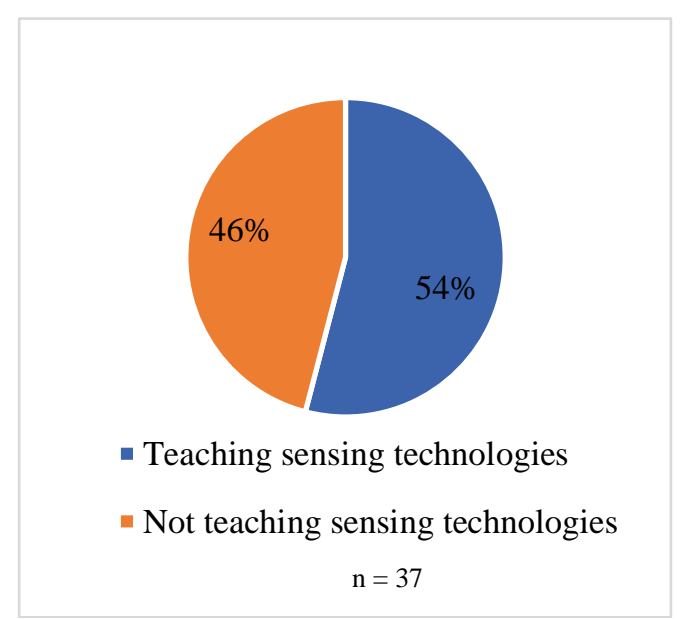

FIG. 10(a): Extent of teaching sensing technologies.

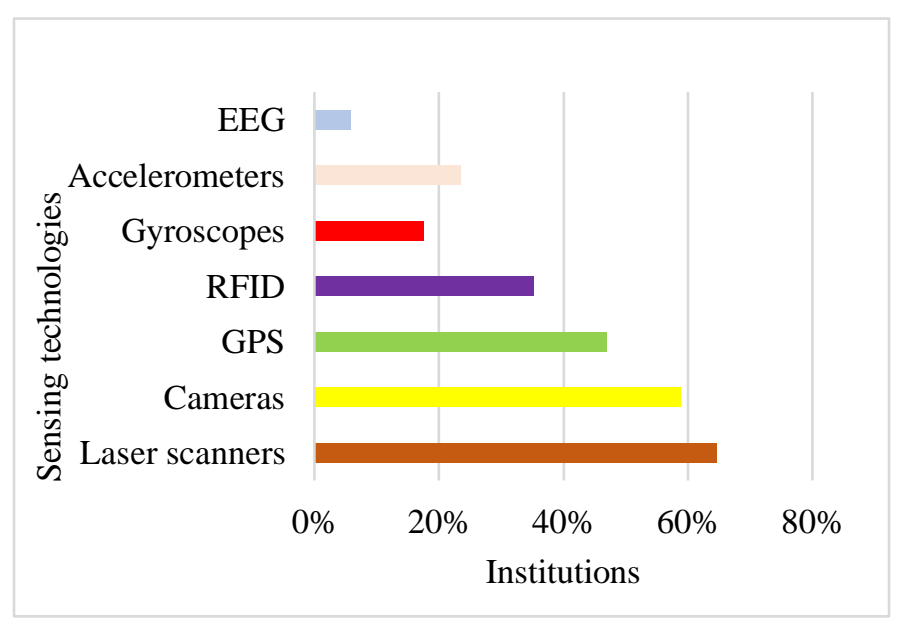

FIG. 10(b): Institutions teaching sensing technology.

\subsection{Industry Case Studies}

Results from the content analysis of the industry case studies on construction applications of sensing technologies showed that laser scanner has been widely used in construction projects. As depicted in Fig. 11, 18 case studies of laser scanner were retrieved. The construction applications of laser scanners extracted from the case studies include the following: measurement of the volume of metal piles, layout of existing mechanical, electrical, and plumbing systems, measuring existing conditions of buildings for renovation purposes, conducting site layout, and generating as-built models of construction projects. 


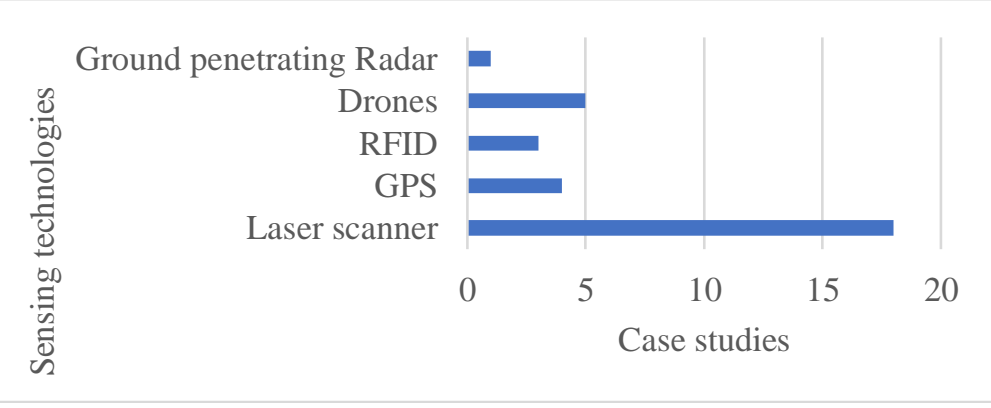

FIG. 11: Sensing technologies identified from the industry case studies.

\subsection{Example Scenario of Stockpile Measurement using Laser Scanner within the HS}

An example of stockpile volume measurement is presented here to indicate the learning process of a laser scanner in the learning environment. The choice of laser scanner as an example is guided by the results of adopted sensing technologies (Fig. 8) and case studies (Fig. 11), which indicates that laser scanner is the most widely used sensing technology. Likewise, the stockpile measurement was selected to depict the application of laser scanner because it is an example of one of the construction activities provided by the industry to which students often experience limited access.

As depicted in Fig. 12, the HS allows students to investigate jobsite characteristics that is, the tasks, operations, and dependencies. Students are also able to explore the context for use of each sensing technology to address risks of construction projects. For example, to measure the volume of a stockpile in the HS, students were able to explore the stockpile on the jobsite and other surrounding activities. Students will need to decide on the possibility of utilizing the laser scanner or any other sensing technologies for the stockpile measurement. The selection of laser scanner for the stockpile measurement will guide the students in understanding the operations of a laser scanner. By clicking the laser scanner button, the laser scanner accessories such as tripod stand, scanner, targets, and scanner interface will appear on the user interface.

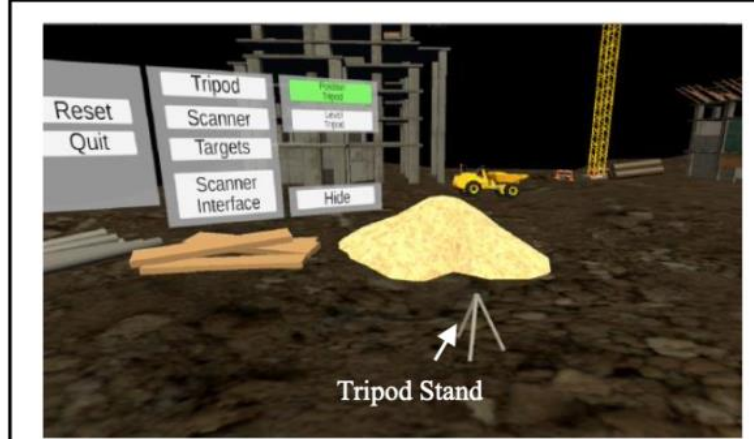

FIG. 12a: Positioning tripod stand

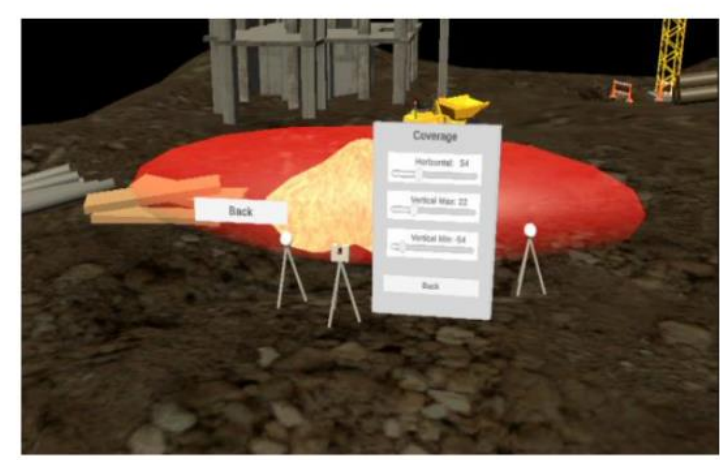

FIG. 12c: Laser scanner coverage

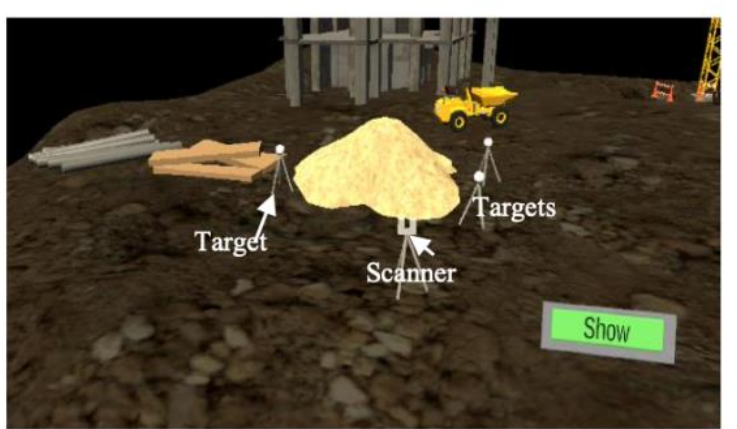

FIG. 12b: Positioning laser scanner and target for stockpile measurement

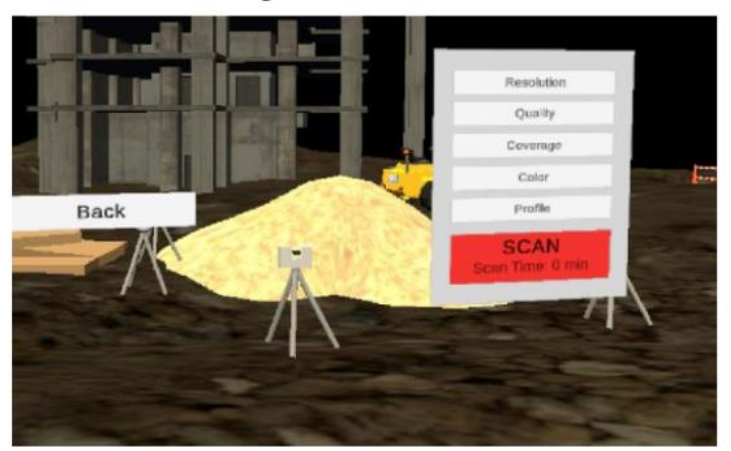

FIG. 12d: Scanner Interface

FIG. 12: Implementation of laser scanner in the HS learning environment. 
As illustrated in Fig. 12a, students will be required to position the tripod of the laser scanner. Students can decide on the most suitable location to place the laser scanner. This is an important step as the placement decision influences the coverage of the laser scanner and the number of scans captured. On selecting the scanner button from the menus on the interface, the scanner appears on the tripod stand. The students can also select and position the targets around the stockpile (Fig. 12b) which has similar consequences as the positioning of the tripod. After positioning the targets, students can interact with the scanner interface. As depicted in Fig. 12c, the interface of the laser scanner allows students to select the coverage, resolution, quality, color, and profile of the scans, which engages their decision-making skills. Students will be propelled to engage all the settings displayed on the scanner interface. This is achieved by deactivating the scan button until all settings on the scanner interface have been engaged (Fig. 12d). This process will educate the students on how resolution and quality can affect time taken to scan a stockpile. The higher the resolution and quality of the scan, the more the time required to scan the stockpile. On the selection of the scan button, the laser scanner commences scanning the stockpile. After the scanning process has been completed, students have the option of viewing the scans, and saving or discarding the completed scans. If the scans are saved, the students can close the HS learning environment and view their scans via the HoloLens.

\subsection{Evaluation}

This section presents the results of the learnability assessment of the learning environment conducted as a focus group discussion with construction industry experts. The section presents the demographics of participants, comments provided about the layout of the learning environment, and representativeness of construction applications of each sensing technology.

\subsubsection{Demographic statistics}

The learnability assessment involved 5 participants who are industry practitioners and current adopters of sensing technologies. While one of the participants has over 20 years' experience, three have between 6-10 years, and one has 0-5years of experience (see Table 5). The participants have an average of 3.5 years of experience with the deployment of the represented sensing technologies and are all familiar with VR or MR environment. It is important to note that the participants are currently using each of the sensing technologies and hence are wellpositioned to provide valuable feedback on the content of the environment for teaching the applications of sensing technologies in the construction industry.

Table 5: Demographic statistics.

\begin{tabular}{|c|c|c|c|c|c|}
\hline Participants & 1 & 2 & 3 & 4 & 5 \\
\hline Age & 32 years & 49years & 35 years & 26years & 33years \\
\hline $\begin{array}{l}\text { Experience with VR or } \\
\text { MR }\end{array}$ & yes & yes & yes & yes & yes \\
\hline Industry experience & 6-10years & above 20 years & 6-10years & 0-5years & 6-10years \\
\hline $\begin{array}{l}\text { Adopted sensing } \\
\text { technologies }\end{array}$ & $\begin{array}{l}\text { Laser scanner, } \\
\text { RFID }\end{array}$ & $\begin{array}{l}\text { Laser scanner, } \\
\text { GPS, Drone }\end{array}$ & $\begin{array}{l}\text { Laser scanner, GPS, } \\
\text { drone, RFID }\end{array}$ & $\begin{array}{l}\text { Laser scanner, } \\
\text { GPS, Drone }\end{array}$ & $\begin{array}{l}\text { Laser scanner, IMU, } \\
\text { Drone }\end{array}$ \\
\hline $\begin{array}{l}\text { Sensing technologies } \\
\text { experience (years) }\end{array}$ & 2 years & 5 years & 6 years & 3.5years & 1 year \\
\hline
\end{tabular}

\subsubsection{Layout of the jobsite}

The focus group questions are categorized into two: (1) general layout of the environment; and (2) feedback on the representativeness of construction applications of the sensing technologies embedded in the learning environment. A total of 50 codes were generated from the focus group discussion and responses with similar themes were further grouped together. Comments regarding the layout of the environment were delineated into materials, activities, gate and fence, and equipment as summarized in Table 6 . The positioning of materials on the jobsite appears very important, as participants commented on designating materials laydown yard, and staging materials at the point of use. Suggestions were made to further improve the representation of the foundation for depicting backfilling. In addition, the participants suggested that grading be added to backfilling which will consequently require additional personnel, and equipment (i.e., a compactor). To further improve the environment, participants suggested a temporary road and wired fence as reflective of a typical jobsite. More safety activities 
(Table 6) were proposed to be added to enrich the learning environment. The participants also commented on the scalability issues of the GameObjects in the environment e.g., increasing the size of the buildings and scaling down the backhoe. Asides from the discussed points, participants commented that the layout of the learning environment was adequate for the learning objective.

Table 6: Layout of the jobsite.

\begin{tabular}{llll}
\hline Materials & Activities & Gate and Fence & Equipment \\
\hline $\begin{array}{l}\text { Stage them at one side, or where } \\
\text { they will be used }\end{array}$ & $\begin{array}{l}\text { For backfilling, include a } \\
\text { compactor }\end{array}$ & Designate entrance and exits & $\begin{array}{l}\text { Move tower crane to serve all } \\
\text { part of building 1 }\end{array}$ \\
\hline $\begin{array}{l}\text { Remove materials from the } \\
\text { entrance }\end{array}$ & $\begin{array}{l}\text { Add worker specifying grades for } \\
\text { backfilling }\end{array}$ & $\begin{array}{l}\text { Create temporary road } \\
\begin{array}{l}\text { Establish materials laydown } \\
\text { yard }\end{array}\end{array}$ Move painter inside a building & $\begin{array}{l}\text { Gesignate another tower crane to } \\
\text { building 2 }\end{array}$ \\
\hline $\begin{array}{l}\text { For backfilling, make a hole to to depict } \\
\text { represent foundation, put a } \\
\text { structure on top }\end{array}$ & $\begin{array}{l}\text { Create pit to simulate 'fall' safety } \\
\text { hazard }\end{array}$ & Change fence to wired fence & Backhoe looks massive \\
\hline Scale-up buildings & Add power lines to the site & \\
\hline & Add caught in-between safety risks & \\
\hline & Add man lift/ scissors lift & \\
\hline
\end{tabular}

\subsubsection{Construction applications of represented Sensors}

The questions in this section were guided by activities represented for each sensor as shown in Table 4. Participants were asked which activities are more representative and which are less representative of their applications on a real jobsite. Where necessary, the participants were required to suggest important activities to be added for each sensor. For the laser scanner, 'renovation' and 'floor flatness' were suggested as the most reflective activities. However, it was suggested that stockpile unloading be removed from the activities stating that the laser scanner provides unwarranted details of stockpile. A participant stated 'So for stockpiles, you need to know by yards or 10s of yards of what you need. It's not down to the millimeters'. It was further added that the drone is preferred for this purpose owning to the data type, and time savings, explaining the need to take multiple scans with the laser scanner, and single video with the drone from a bird-eye view. However, a participant stated that the laser scanner is used for this purpose during backfilling. To further buttress this, another participant explained that their company currently employs drone scanner (scanner mounted on drones) for stockpile volumetric measurement. Regarding the operational characteristics of the laser scanner, it was suggested that 'Field survey' be included as the first step of operating the laser scanner. The participant stated, 'let's say if you're scanning stuff, the first thing you do is walk around the space because every time the field condition could be changed'.

Table 7: Feedback on represented construction applications of each sensor.

\begin{tabular}{|c|c|c|c|c|c|}
\hline & Laser scanner & GPS & Drone & IMU & RFID \\
\hline \multirow{3}{*}{ Comments } & $\begin{array}{l}\text { Floor flatness and } \\
\text { Renovations are most } \\
\text { reflective }\end{array}$ & $\begin{array}{l}\text { Backfilling and } \\
\text { material delivery } \\
\text { are most reflective }\end{array}$ & $\begin{array}{l}\text { All activities are } \\
\text { reflective }\end{array}$ & $\begin{array}{l}\text { Replace painting and } \\
\text { carpentry with high- } \\
\text { risk activities }\end{array}$ & $\begin{array}{l}\text { Material inventory } \\
\text { and safety risks are } \\
\text { most reflective }\end{array}$ \\
\hline & $\begin{array}{l}\text { Stockpile unloading is } \\
\text { hardly done - data overkill }\end{array}$ & $\begin{array}{l}\text { Crane loading not } \\
\text { representative }\end{array}$ & $\begin{array}{l}\text { Add safety and quality } \\
\text { checks }\end{array}$ & & $\begin{array}{l}\text { Show a worker with } \\
\text { an RFID reader }\end{array}$ \\
\hline & $\begin{array}{l}\text { Drone scanners are used } \\
\text { for stockpile measurement }\end{array}$ & $\begin{array}{l}\text { Remove material } \\
\text { handling }\end{array}$ & $\begin{array}{l}\text { Add tracking if } \\
\text { Roofers are well tied }\end{array}$ & & \\
\hline \multirow{4}{*}{$\begin{array}{l}\text { Suggested } \\
\text { activities }\end{array}$} & $\begin{array}{l}\text { Rename renovation as } \\
\text { field measurement }\end{array}$ & $\begin{array}{l}\text { Carpentry and } \\
\text { painting should be } \\
\text { removed }\end{array}$ & $\begin{array}{l}\text { Tracking Workers } \\
\text { safety in a controlled } \\
\text { access zone }\end{array}$ & $\begin{array}{l}\text { Consider adding } \\
\text { Masonry }\end{array}$ & $\begin{array}{l}\text { Geofence to check } \\
\text { workers in and out }\end{array}$ \\
\hline & $\begin{array}{l}\text { Add 'field survey area' as } \\
\text { first step of laser scanning }\end{array}$ & Add layout activity & $\begin{array}{l}\text { Tracking Missing } \\
\text { window installation }\end{array}$ & framing & $\begin{array}{l}\text { Implement for other } \\
\text { safety activities }\end{array}$ \\
\hline & $\begin{array}{l}\text { Additional activities- } \\
\text { settlement, and } \\
\text { underpinning }\end{array}$ & $\begin{array}{l}\text { Tracking equipment } \\
\text { fleet }\end{array}$ & $\begin{array}{l}\text { Volumetric } \\
\text { measurement }\end{array}$ & Include drywall & \\
\hline & & $\begin{array}{l}\text { Add grading to } \\
\text { existing backfilling }\end{array}$ & $\begin{array}{l}\text { Quality checks in } \\
\text { difficult to reach areas }\end{array}$ & & \\
\hline
\end{tabular}


For the GPS, backfilling, tracking equipment, material delivery, and personnel movement are the most reflective activities. Crane loading are more pre-defined and was suggested to be removed. Participants suggested grading, and equipment fleet as additional activities. Carpentry and painting are least reflective and was suggested to be removed. A participant stated that privacy concerns will also be an issue in personnel tracking. Participants commented that all drone activities were reflective of real jobsite activities. Participants suggested that volumetric measurement be added for the drone. Further questions were asked about additional safety activities to be included for the drone, and 'Tracking roofers' safety', 'workers on leading-edge', 'falls', 'caught in-between working equipment', were suggested. Painting and carpentry activities represented for IMU were recommended to be replaced with masonry, framing, and drywall. The participant stated, 'you want to put your high-risk activity'. Participants stated that RFID for material inventory and capturing safety risks as represented in material handling (2) are most reflective. However, participants advised including a worker and a RFID reader to supplement RFID activities. They also suggested that a geo-fence be represented in the environment to track workers who enter and exit the site, and that RFID should be used for other suggested safety risks.

\section{DISCUSSION}

This paper presents the design and evaluation of an HS learning environment for teaching sensing technologies in construction education. The learning content of the environment is informed by results from the survey of industry practitioners and construction industry case studies of the applications of sensing technologies. In addition, this study surveyed construction engineering instructors to assess the extent to which sensing technology related contents are being taught in institutions.

Results from the industry survey reveal a high rate of adoption of sensing technologies in the construction industry. The top four identified sensing technologies from the survey and industry case studies are laser scanner, drone, RFID, and GPS. While $80 \%$ of the surveyed industry practitioners are adopting sensing technologies, $54 \%$ of faculty members are teaching sensing technologies. This implies that academia is lagging the industry in preparing future workforce with the required technical competencies for implementing sensing technologies. This is supported by Wu et al. (2018) who stated that there is a severe shortage of skilled workforce and emphasized the need to equip future workforce with domain-specific competencies. The skill gap can also be due to inability of under-resourced institutions to invest in sensing technologies and technology deployment challenges such as limited or no access to construction sites, inability of construction companies to accommodate large class sizes, and weather and schedule constraints.

Inspired by opportunities offered by MR environment and the ease of use as an interactive hands-on learning environment, this study presents the development of a MR environment for learning sensing technologies. Top identified sensing technologies from surveys and case studies, and the corresponding constructions applications were leveraged for developing the interactive HS learning environment. Appropriate MRTK tools were employed to reduce cognitive overload and improve navigation in the learning environment. The environment was structured as three different scenes developed to scaffold students' learning process of construction activities and sensing technologies. Within the learning environment, students can explore the digitally represented activities and associated risks and resources in the 'explore jobsite' scene. Thereafter, students can explore and learn the suitability of each sensing system for mitigating the construction risks before implementing them in the 'sensor implementation' scene.

Before implementing the learning environment in classrooms, it is important to validate the quality, representation, and appropriateness of the learning contents with construction industry practitioners who are proficient with sensing technologies. Wu et al. (2020) reported the importance of quality control during the design and implementation of MR learning environments and how it can impact achievable educational benefits from the learning environment. According to Abdelaziz et al. (2014), one of the challenges of virtual learning environments is virtual simulation of learning contents, and the successful design of a learning environment is often an iterative process involving formative evaluations. In this regard, a learnability assessment in the form of a formative evaluation of the learning environment was conducted with construction industry professionals. Results from the learnability assessment revealed that the layout of the virtual construction site typically, the fence, gates, and material laydown yards is critical to simulating a real jobsite.

Overall, participants validated the layout of the environment for its learning purpose. However, there were varying opinions regarding the represented construction applications of each sensing technology. For the laser scanner, 
participants agreed that represented floor flatness and renovation activities were very reflective of how it is used on the jobsite, but their opinions differed for the 'stockpile unloading' activity. Three participants agreed while the other two disagreed on the inclusion of 'stockpile unloading' for depicting laser scanning in the learning environment. One of the participants who uses laser scanner for this purpose explained how they currently employ a laser scanner mounted on drone for stockpile measurement. This may be a recent innovation, which other participants are yet to employ on their jobsites. It is important that students learn how to use the laser scanner for this purpose, thus validating its inclusion in the learning environment. Furthermore, participants explained that represented drone activities are reflective of their applications on real jobsite. Generally, the participants suggested more safety-related activities such as 'caught in-between', fall, 'tracking roofers' safety', 'tracking workers on leading-edge', 'discovering potential falls', and 'caught in-betweens'. Two of these activities: 'tracking workers on leading-edge', and 'discovering potential falls' are currently represented as manual material handling (2) in the learning environment. It was also proposed that the drone be implemented for capturing site sanitation and quality checks. Participants recommended that the represented activities for GPS be reduced, by removing trade work like labor, carpentry, and painting. It was however suggested that backfilling be expanded to capture grading as typically performed on the jobsite. Importantly, activities represented for the IMU were suggested to be replaced with high-risk activities. Not much was suggested for IMU, as most participants were not so proficient with the use of this sensor. Generally, using RFID for material inventory was agreed as reflective, but there were suggestions to expand this sensor for tracking more safety issues on the jobsite.

While the newly suggested activities are important, not all can be implemented in the learning environment to avoid congestion. However, the activities suggested to be removed will be implemented, and emphasis will be placed on adding suggested health and safety risks to the learning environment. This is important as safety continues to be a major concern on construction sites. This was also revealed in the learnability assessment, as additional activities suggested for most of the sensing technologies like drones, RFID, and IMU are health and safety related.

\section{CONCLUSIONS AND FUTURE WORK}

The need for timely and efficient completion of construction projects has resulted in a growing rate of adoption of sensing technologies in the construction industry. This in turn has triggered the need for future construction workforce with the necessary technical skills for deploying sensing technologies on construction projects. This paper presents the development of learning environment that affords learners an experiential opportunity to acquire sensing systems application knowledge and improve their risk-identification abilities. The study revealed a technical skill gap for deploying sensing technologies in the construction industry, and a need to equip future workforce with the required skills. The study further presented professional feedback on specific domain skills to be represented within a MR environment to develop technical skills of the future workforce in sensing technologies. Based on the feedback, the learning environment can be optimized for teaching sensing technologies.

There are some limitations to this study that paves way for future research. Due to the COVID-19 pandemic, the evaluation was conducted online, hence, participants could not individually walk through the environment. By simulating their sense of presence, their evaluation and perceptions of the learning environment could have been influenced. Participants could also have provided usability issues of the learning environment. The study was not evaluated with potential users such as students of construction engineering and management. Therefore, future work will involve the following:

- Conducting usability studies with students to identify learnability, ease of use, ease of learning, and overall satisfaction with the HS learning environment.

- Conducting a comparative analysis of student groups to investigate the potential of virtual sensors within the HS learning environment to enhance addressing construction problems.

- Development of tangible interactive interface for the learning environment.

- Extension of the HS learning environment for equipping the future and current workforce with experiential training opportunities in other areas e.g., health and safety, and fire safety.

\section{ACKNOWLEDGEMENT}

This is a substantially extended and enhanced version of the paper presented at the 20th International Conference on Construction Applications of Virtual Reality (CONVR 2020). We would like to acknowledge the editorial 
contributions of Professor Nashwan Dawood and Dr. Farzad Rahimian of Teesside University in the publication of this paper.

This material is based upon work supported by the National Science Foundation (Award \#: IUSE - 1916521). Any opinions, findings, and conclusions or recommendations expressed in this material are those of the authors and do not necessarily reflect the views of the NSF.

\section{REFERENCES}

Abdelaziz, M. A., Alaa El Din, M. \& Senousy, M. B. (2014), "Challenges and issues in building virtual realitybased e-learning system", International Journal of e-Education, e-Business, e-Management and $e$ Learning, Vol. 4, No. 4, 320.

Akanmu, A. \& Olayiwola, J. (2019). "Interactive Holographic Scenes for Teaching Wireless Sensing in Construction Engineering and Management". Proceeding CIBW78, 2019.

Andreasen, M. S., Nielsen, H. V., Schrøder, S. O. \& Stage, J. (2007). "What happened to remote usability testing? An empirical study of three methods". Proceedings of the SIGCHI conference on Human factors in computing systems, 2007. 1405-1414.

Azhar, S., Kim, J. \& Salman, A. (2018). "Implementing Virtual Reality and Mixed Reality Technologies in Construction Education: Students' Perceptions and Lessons Learned". 11th annual International Conference of Education, 2018.

Bada, S. O. \& Olusegun, S. (2015), "Constructivism learning theory: A paradigm for teaching and learning", Journal of Research \& Method in Education, Vol. 5, No. 6, 66-70, doi: 10.9790/7388-05616670.

Beatty, B. (2016). "Balfour Beatty Awarded $\$ 196$ Million North Block at Capitol Crossing Contract". Available at: https://www.balfourbeattyus.com/our-company/media/press-releases/balfour-beatty-awarded-\$196million-north-block-at.

Bosché, F., Abdel-Wahab, M. \& Carozza, L. (2016), "Towards a mixed reality system for construction trade training", Journal of Computing in Civil Engineering, Vol. 30, No. 2, 04015016.

Choe, S., Leite, F., Seedah, D. \& Caldas, C. (2013). Application of sensing technology in the prevention of backing accidents in construction work zones. Computing in Civil Engineering (2013).

Chrastil, E. R. \& Warren, W. H. (2013), "Active and passive spatial learning in human navigation: acquisition of survey knowledge", Journal of experimental psychology: learning, memory, and cognition, Vol. 39, No. 5,1520 .

Clay, R. (2020). "Conducting research during the COVID-19 pandemic". Available at: http://www.apa.org/news/apa/2020/03/conducting-research-covid-19.

Deutsch, J. A., Lewis, J. A., Whitworth, E., Boian, R., Burdea, G. \& Tremaine, M. (2005), "Formative evaluation and preliminary findings of a virtual reality telerehabilitation system for the lower extremity", Presence: Teleoperators \& Virtual Environments, Vol. 14, No. 2, 198-213.

Edelson, D. C. (2001), "Learning-for-use: A framework for the design of technology-supported inquiry activities", Journal of Research in Science teaching, Vol. 38, No. 3, 355-385.

Getuli, V., Capone, P. \& Bruttini, A. (2019). Game technology and Building information Modelling for the adoption of Virtual Reality in construction safety training: a prototype protocol. 36th CIB W78 Conference - Advances in ICT in Design, Construction and Management in Architecture, Engineering, Construction and Operations (AECO) Newcastle (UK).

Getuli, V., Capone, P. \& Bruttini, A. (2020a), "Planning, management and administration of HS contents with BIM and VR in construction: an implementation protocol", Engineering, Construction and Architectural Management, Vol., No.

Getuli, V., Capone, P., Bruttini, A. \& Isaac, S. (2020b), "BIM-based immersive Virtual Reality for construction workspace planning: A safety-oriented approach", Automation in Construction, Vol. 114, No. 103160. 
Getuli, V., Giusti, T., Capone, P., Sorbi, T. \& Bruttini, A. (2018), "A project framework to introduce virtual reality in construction health and safety", IN_BO. Ricerche e progetti per il territorio, la città e l'architettura, Vol. 9, No. 13, 166-175.

Gonczi, A. (1999). "12 Competency-based learning".

Greeno, J. G. (1998), "The situativity of knowing, learning, and research", American psychologist, Vol. 53, No. 1,5 .

Greeno, J. G. \& Engeström, Y. (2006). "Learning in activity", na.

Hallowell, M. R., Teizer, J. \& Blaney, W. (2010). "Application of sensing technology to safety management". Construction Research Congress 2010: Innovation for Reshaping Construction Practice, 2010. 31-40.

Hannon, J. J. (2007). "Emerging technologies for construction delivery", Transportation Research Board.

Huber, D., Akinci, B., Tang, P., Adan, A., Okorn, B. \& Xiong, X. (2010). Using laser scanners for modeling and analysis in architecture, engineering, and construction. 2010 44th Annual Conference on Information Sciences and Systems (CISS). IEEE.

Jang, W.-S. \& Skibniewski, M. J. (2009), "Cost-benefit analysis of embedded sensor system for construction materials tracking", Journal of Construction Engineering and Management, Vol. 135, No. 5, 378-386, doi: 10.1061/(ASCE)0733-9364(2009)135:5(378).

Kapliński, O. (2018), "Innovative solutions in construction industry. Review of 2016-2018 events and trends", Engineering Structures and Technologies, Vol. 10, No. 1, 27-33, doi: 10.3846/est.2018.1469.

Kim, J. \& Irizarry, J. (2020), "Evaluating the use of augmented reality technology to improve construction management student's spatial skills", International Journal of Construction Education and Research, Vol., No. 1-18.

Ko, C.-H. (2010), "RFID 3D location sensing algorithms", Automation in Construction, Vol. 19, No. 5, 588-595.

Lave, J. \& Wenger, E. (1991). "Situated learning: Legitimate peripheral participation", Cambridge university press.

Lehman, S. M. \& Tan, C. C. (2021). Leveraging Edge Computing for Mobile Augmented Reality. Fog/Edge Computing For Security, Privacy, and Applications. Springer.

Liu, Y. (2014). "Virtual neurosurgical education for image-guided deep brain stimulation neurosurgery". 2014 International Conference on Audio, Language and Image Processing, 2014. IEEE, 623-626.

$\mathrm{Lu}$ Lu, A. (2019). "Large Scale Immersive Holograms with Microsoft Hololens". https://addi.ehu.eus/handle/10810/36706.

Lu, M., Chen, W., Shen, X., Lam, H.-C. \& Liu, J. (2007), "Positioning and tracking construction vehicles in highly dense urban areas and building construction sites", Automation in Construction, Vol. 16, No. 5, 647656.

Maffei, A. \& Onori, M. (2019). "Evaluation of the potential impact of fully-immersive virtual reality on production engineering curricula". 2019 IEEE AFRICON, 2019. IEEE, 1-5.

Marks, E. \& Teizer, J. (2012). Proximity sensing and warning technology for heavy construction equipment operation. Construction research congress 2012: Construction challenges in a flat world.

Messner, J. I., Yerrapathruni, S. C., Baratta, A. J. \& Whisker, V. E. (2003). "Using virtual reality to improve construction engineering education". American Society for Engineering Education Annual Conference \& Exposition, 2003.

Milgram, P. \& Kishino, F. (1994). "A Taxonomy of Mixed Reality Visual Displays". IEICE Transactions on Information and Systems, 1994.

Miller, J. (2008). "Skanska Uses Vela Systems on New Meadowlands Stadium Construction Project to Unite RFID and BIM for Materials Tracking". Cision. Available at: https://www.prweb.com/releases/2008/04/prweb821184.htm. 
Oloufa, A. A., Ikeda, M. \& Oda, H. (2003), "Situational awareness of construction equipment using GPS, wireless and web technologies", Automation in Construction, Vol. 12, No. 6, 737-748.

Pan, Z., Cheok, A. D., Yang, H., Zhu, J. \& Shi, J. (2006), "Virtual reality and mixed reality for virtual learning environments", Computers \& graphics, Vol. 30, No. 1, 20-28, doi: 10.1016/j.cag.2005.10.004.

Pantelidis, V. S. (2010), "Reasons to use virtual reality in education and training courses and a model to determine when to use virtual reality", Themes in Science and Technology Education, Vol. 2, No. 1-2, 59-70.

Psotka, J. (1995), "Immersive training systems: Virtual reality and education and training", Instructional science, Vol. 23, No. 5-6, 405-431.

Radu, I. (2014), "Augmented reality in education: a meta-review and cross-media analysis", Personal and Ubiquitous Computing, Vol. 18, No. 6, 1533-1543.

Shanbari, H., Blinn, N. \& Issa, R. R. (2016), "Using augmented reality video in enhancing masonry and roof component comprehension for construction management students", Engineering, Construction and Architectural Management, Vol., No.

Shirazi, A. \& Behzadan, A. H. (2015), "Design and assessment of a mobile augmented reality-based information delivery tool for construction and civil engineering curriculum", Journal of professional issues in engineering education and practice, Vol. 141, No. 3, 04014012.

Skanska. (2009). "Rocky Mountain Arsenal". Available at: https://www.usa.skanska.com/what-wedeliver/projects/57219/Rocky-Mountain-Arsenal/.

Song, J., Haas, C. T. \& Caldas, C. H. (2006), "Tracking the location of materials on construction job sites", Journal of Construction Engineering and Management, Vol. 132, No. 9, 911-918, doi: 10.1061/(ASCE)07339364(2006)132:9(911).

Teizer, J. (2008), "3D range imaging camera sensing for active safety in construction", Journal of Information Technology in Construction (ITcon), Vol. 13, No. 8, 103-117.

Thomsett-Scott, B. C. (2006), "Web site usability with remote users: Formal usability studies and focus groups", Journal of Library Administration, Vol. 45, No. 3-4, 517-547.

Tixier, A., Albert, A. \& Hallowell, M. R. (2013). "Teaching construction hazard recognition through high fidelity augmented reality". Proc., 2013 American Society of Engineering Education Annual Conf, 2013. 123.1139.

Tullis, T., Fleischman, S., McNulty, M., Cianchette, C. \& Bergel, M. (2002). "An empirical comparison of lab and remote usability testing of web sites". Usability Professionals Association Conference, 2002.

Turkan, Y., Bosche, F., Haas, C. T. \& Haas, R. (2012), "Automated progress tracking using 4D schedule and 3D sensing technologies", Automation in construction, Vol. 22, No. 414-421.

Turner. (2016). "Turner project team at North Eagleville Road Phase IIIA project achieves substantial completion". Turner Construction Available https://www.turnerconstruction.com/news/item/9170/Turner-project-team-at-North-Eagleville-RoadPhase-IIIA-project-achieves-substantial-completion.

V. Getuli, V., Capone, P., Bruttini, A. \& Sorbi, T. (2020). A proposal of a site object library for construction workers' safety training using BIM-based immersive virtual reality. 20th International Conference on Construction Applications of Virtual Reality Middlesbrough.

Vasilevski, N. \& Birt, J. (2020), "Analysing construction student experiences of mobile mixed reality enhanced learning in virtual and augmented reality environments", Research in Learning Technology, Vol. 28, No.

Weston, T. (2004), "Formative evaluation for implementation: Evaluating educational technology applications and lessons", American Journal of Evaluation, Vol. 25, No. 1, 51-64.

Wu, W., Sandoval, A., Gunji, V., Ayer, S. K., London, J., Perry, L., Patil, K. \& Smith, K. (2020), "Comparing Traditional and Mixed Reality-Facilitated Apprenticeship Learning in a Wood-Frame Construction Lab", Journal of Construction Engineering and Management, Vol. 146, No. 12, 04020139. 
Wu, W., Tesei, A., Ayer, S., London, J., Luo, Y. \& Gunji, V. (2018). "Closing the Skills Gap: Construction and Engineering Education Using Mixed Reality-A Case Study". 2018 IEEE Frontiers in Education Conference (FIE), 2018. IEEE, 1-5.

Zhang, Y. \& Lu, L.-W. (2008), "Introducing smart structures technology into civil engineering curriculum: education development at Lehigh University", Journal of Professional Issues in Engineering Education and Practice, Vol. 134, No. 1, 41-48, doi: 10.1061/(ASCE)1052-3928(2008)134:1(41). 